\title{
ПЕРСПЕКТИВЫ РАЗВИТИЯ ТОРГОВО-ЭКОНОМИЧЕСКИХ ОТНОШЕНИЙ МЕЖАУ АРМЕНИЕЙ И ИРАНОМ
}

\begin{abstract}
Аннотауия. Предмет. В статье рассматриваются вопросы эффективного сотрудничества Армении и Ирана с точки зрения торговли и инвестииий. Џель работы. Џелью данной работы является выявление взаимовыгодных сфер армяно-иранского торговоэкономического сотрудничества. Методология проведения работы. При выявлении взаимовыгодных торговых и инвестииионных сфер экономики Армении и Ирана нами были использованы методы расчета выявленных сравнительных и потенциальных преимуществ. Результаты работы. В результате проведенной работы представлены те сферы, в которых страны могут развивать взаимную торговлю в краткосрочном периоде, а также те сферы, в которых обе страны могут расиирить и диверсифииировать свой экспорт. Также на основе проведенных расчетов нами были выявлены взаимовыгодные сферы для инвестииий. Выводы. Торговое и инвестииионное сотрудничество между Арменией и Ираном обладает большим потенииалом, который еще не используется в полной мере. Это может стать хорошей возможностью для Армении диверсифииировать как экспортную корзину, так и инвестииионный портфель. Таким образом, можно постепенно ослабить зависимость от одного или нескольких крупных инвесторов или торгового партнера, что будет способствовать дальнейшему устойчивому развитию эконо-

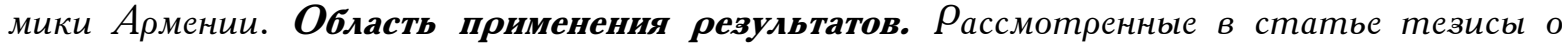
взаимовыгодной двусторонней торговле, а также об эффективных инвестициях могут быть полезны для дальнейших исследований на эту теме для авторов обучающих программ, а также для государственных органов Армении и Ирана при разработке программ развития двустороннего сотрудничества.
\end{abstract}

Ключевые слова: армяно-иранская торговля, инвестииии, перспективные сферы, выявленные и потенциальные сравнительные преимущества.

SARGSYAN LILIT NORAYROVNA

Candidate of Economic Sciences, Research Associate of the Institute of Economics named after M. Kotanyan of the National Academy of Sciences of the Republic of Armenia, e-mail: sarg.lilit@yahoo.com

\section{THE PROSPECTS OF DEVELOPMENT OF TRADE ECONOMIC RELATIONS BETWEEN ARMENIA AND IRAN}

\begin{abstract}
The subject. The manuscript discusses the issues of effective cooperation between Armenia and Iran from the points of view of trade and investments. The goal of the study. The goal of this study is finding mutually beneficial areas for Armenian-Iranian trade economic cooperation. The methodology of completing the study. When finding mutually beneficial trade and investment areas of economy of Armenia and Iran, we have used the methods of calculation of relative and potential identified advantages. The results of the study. As a result of the study competed we have suggested the areas where countries can develo $\rho$ bilateral trade in the short term, as well as those spheres where the countries could expand and diversify their export. Also, based on the calculations completed, we have found spheres for investments that would be mutually beneficial. The conclusions. Trade and investment cooperation between Armenia and Iran has a great potential that hasn't been fully used yet. This may become a good opportunity for Armenia to diversify both its export basket, and its investment portfolio. Therefore, it would be possible to gradually reduce the dependence upon one or several large investors or a trading partner which will assist in further sustainable development of the economy of Armenia. The area
\end{abstract}


of application of the results. The points discussed in the manuscript regarding mutually beneficial bilateral trade, as well as regarding effective investments may be useful for further studies of this topic, for authors of educational programs, as well as for the governmental authorities of Armenia and Iran when drafting programs of development of bilateral cooperation.

Keywords: Armenian-Iranian trade, investments, promising spheres, identified and potential relative advantages.

Введение. Армяно-иранские торгово-экономические отношения начали свое развитие с первых же дней независимости Республики Армения (далее - РА). Исламская Республика Иран (ИРИ) была одной из первых стран, официально признавших независимость Республики Армения и установивших дипломатические и экономические отношения с Арменией. С момента обретения независимости Армения находится в дружеских отношениях только с двумя из ее четырех соседних стран, поэтому дружеские отношения с соседним Ираном значительно помогли стране преодолеть постсоветский кризис.

Тем не менее армяно-иранские торгово-экономические отношения все еще не имеют больших объемов. Объемы импорта из Армении в Иран, а также из Ирана в Армению все еще невелики. В Армении нет стабильных иранских инвестиций, а официальные статистические данные об инвестициях Армении в ИРИ просто отсутствуют. Это связано с многочисленными обстоятельствами. В первую очередь, рынок Армении очень мал для привлечения крупных инвестиций, и с точки зрения торговли часто соотношение качества и цены бывает неприемлемым для продажи продуктов как на иранском, так и на армянском рынке.

Надо отметить, что вышеприведенные аргументы остались неизменными до 2015 года. Однако в 2015 году ситуация резко изменилась как с точки зрения Армении, так и с точки зрения ИРИ. В 2015 году Армения стала членом Евразийского экономического союза. Тем самым для инвесторов Армении открываются двери на огромный рынок ЕАЭС. А в Иране другая ситуация. В 2015 году постепенно сокращаются экономические санкции против ИРИ, что может сделать иранский рынок более открытым и прозрачным для других стран, в том числе для инвесторов из Армении.

Таким образом, можно сказать, что 2015-й стал переломным годом, позволившим в новом свете наблюдать за развитием армяно-иранских торгово-экономических отношений и выработать основу для перспективного развития.

Анализ литературы. Внешняя торговля и прямые иностранные инвестиции (далее - ПИИ) являются неотьемлемой частью экономического развития каждой страны. В экономической литературе есть многочисленные анализы, которые указывают на взаимосвязь внешней торговли и ПИИ, а также на их значительную роль в достижении экономического роста. Два компонента внешней торговли каждой страны - экспорт и импорт - указывают на уровень экономического развития данной страны.

В 2000 году Доллар и Краай провели анализ среди стран мира, разделяя их на 3 группы страны с высокими доходами, которые после Второй мировой войны внедрили политику свободной торговли, развивающиеся страны, которые внедрили политику свободной торговли после 1980-х годов, и развивающиеся страны, которые не внедрили политику свободной торговли после 1980-х годов. В результате авторы показали, что в 1960-х годах темпы экономического роста были высоки в странах с высокими доходами, то есть в тех странах, которые в данный период уже внедрили политику свободной торговли. В 1970-х годах экономический рост был почти одинаковым во всех странах, а вот в 1980-1990-х годах в развивающихся странах, которые внедрили политику свободной торговли, темпы экономического роста были намного выше, чем в других развивающихся странах, которые пока что не усвоили свободу торговли, а также чем в странах с высоким уровнем доходов [8, стр. 22-49].

Таким образом, можно констатировать тот факт, что свобода торговли позитивно влияет на экономический рост страны.

А какая связь существует между ПИИ и экономическим ростом? Этим вопросом задавались многие экономисты.

По определению Международного валютного фонда, ПИИ указывает на намерение полу- 
чить доход резидента из любой страны через внедрение финансов в капитал предприятия, работающего в другой стране [10, Р. 6].

Согласно определению ВТО, ПИИ представляет собой тип инвестиций, во время которых инвестор страны закладывает свои активы в другой стране при условии, что он получает контроль над активами [18, стр. 129].

Первые теории об инвестициях были предложены в 1950-х и 1960-х годах, когда американские дочерние компании увеличили свою деятельность на европейском и латиноамериканском рынках. С этого момента прямые инвестиции значительно выросли и продолжают расти до наших дней.

Между тем теории о внешней торговле были предложены задолго до этого. Первые тезисы о внешней торговле были предложены школой меркантилизма. Они твердили, что наилучшим образом экономический рост можно обеспечивать с помощью политики протекционизма [11, P. 15-25]. Далее уже были предложены теории сторонников либерализации, которые думают, что экономика может расти только тогда, когда страна ведет политику либерализации торговли, так как таким образом в стране производится более эффективное распределение ресурсов [5, Р. 25-37]. Сторонниками данной теории являются особенно представители классической теории. Смит и Рикардо своими теориями $[1, \mathrm{p} .11]$ доказали, что либерализация торговли наилучшим образом влияет на экономический рост страны [14, p. 10-38]. Как показывают результаты анализов разных авторов, в течение некоторого времени свобода торговли приводит к притоку ПИИ, а также позитивно влияет на экономический рост страны [17, стр. 187-231]. Так, свобода торговли привлекает в страну иностранных инвесторов, этим и прибавляет спрос на качественную рабочую силу, что и приводит к увеличению объемов инвестиций в сфере образования. А это, естественно, влияет не только на развитие экономики, но и на благосостояние народа. Таким образом, нужно заметить, что влияние ПИИ на экономический рост намного выше в странах, которые внедрили политику свободы торговли.

Работы некоторых экономистов показывают, что при увеличении удельного веса ПИИ в ВВП на $1 \%$ экономический рост прибавляется на 0,3 \% [7, стр. 445-502]. Другой анализ показывает, что если в США доля основного капитала в ВВП увеличить на $1 \%$, то в следующем году ВВП увеличится на $0,12 \%$ [19, стр. 232].

Как показывает мировой опыт, в странах с высоким экономическим ростом индекс инвестиции/ВВП находится в диапазоне $22-41,3 \%$ (22 \% - в Тайване, а 41,3 - в Сингапуре). Что касается стран с низким экономическим ростом, то данный индекс колеблется от $15,4 \%$ до $21,8 \%$, то есть в среднем в странах с высоким экономическим ростом данный индекс составляет $31 \%$, а в странах с низким экономическим ростом - почти что в двое ниже (19\%). Таким образом, можно сказать, что страны мира на капитальные инвестиции отводят около 20 \% своего ВВП [13, стр. 62-78]. В Армении этот показатель намного ниже - около $12 \%$.

А вот другие экономисты твердят, что наибольшую выгоду страна может извлечь при специализации на производство таких товаров, в которых имеет конкурентные преимущества [3, p. 99-117; 4, p. 11-23; 15, p. 112-143]. Таким образом, из этого вытекает вопрос: кто прав сторонники протекционизма или же сторонники либерализации? Однако, как показывает опыт разных стран, данный вопрос не имеет окончательного ответа-протекционистская или либеральная политика будут влиять на экономический рост в той или иной степени. Все зависит от уровня развития страны. Например, после распада СССР в странах союза было необходимо применить политику протекционизма, а в развитых странах в основном наибольшую эффективность обеспечивает либеральная политика. Таким образом, можно сказать, что сторонники классической школы рассмотрели тезисы меркантилистов вне той реальности, для которой они были созданы, поэтому и пришли к такому разногласию.

Понятно, что классические и неоклассичские школы экономики не могли быть научной основой для изучения внешней торговли и ПИИ, поскольку идеология этих школ основывалась на том принципе, что ресурсы совершенно мобильны внутри страны и не мобильны между странами.

Обычно в экспорте стран со слабой экономикой преобладают сырьевые продукты, в то время как импорт включает готовые продукты, а в развитых странах - наоборот [2, p. 63-66; 9, p. 32, 16; p. 137-159]. Тем не менее даже самые передовые страны не могут производить и экс- 
портировать все виды товаров. В зависимости от погодных условий, имеющихся ресурсов и других обстоятельств экономика страны может обладать сравнительным или конкурентным преимуществом.

Но многими экономическими расчетами доказано, что специализация страны по сравнительным преимуществам позволяет экономике достичь более высоких темпов экономического роста. Таким образом, оказывается, что не только импорт сырья может благотворно влиять на развитие страны, но и импорт готовой продукции, в производстве и в экспорте которой страна не обладает сравнительным преимуществом, так как импорт таких продуктов позволяет более эффективно распределить ресурсы внутри страны.

Методы. Целью данной статьи является выявление взаимовыгодных сфер армяноиранского таргово-экономического сотрудничества.

Для этого нами была анализирована основная литература на эту тему как с точки зрения торговли в теоретическом плане, так и с точки зрения инвестиционного сотрудничества. Для анализа нами были использованы методы расчета выявленных сравнительных и потенциальных преимуществ.

Результат. На самом деле с точки зрения развития каждой страны очень важно определить сферы, в производстве которых страна имеет сравнительные преимущества. На этой же основе будут определены наиболее эффективные товарные группы с точки зрения экспорта и импорта, также будет разработана соответствующая внешняя политика.

Что касается ПИИ, то этот метод позволяет стране экономически развиваться за счет капитала других стран, не прибавляя внешний долг.

Понятно, однако, что иностранные инвестиции не могут быть реализованы во всех секторах экономики, поскольку иностранный инвестор в первую очередь считает, что он должен получить максимальную прибыль, и не будет инвестировать в неэффективные сферы экономики. Таким образом с точки зрения привлечения ПИИ также важно раскрывать области, имеющие сравнительные преимущества и представить их в наилучшем свете иностранным инвесторам. Очень важно также создание благоприятной инвестиционной среды [6, p. 15-20; 12, p. 688-718]. Учитывая эти обстоятельства, в статье будут представлены перспективы развития армяно-иранских экономических отношений.

Армяно-иранские торгово-экономические отношения начались с первых дней независимости Республики Армения (далее - РА). Исламская Республика Иран (ИРИ) была одной из первых стран, официально признавших независимость Республики Армения и установивших дипломатические и экономические отношения с Арменией. С момента обретения независимости Армения находится в дружеских отношениях с двумя из ее четырех соседей, поэтому дружеские отношения с соседним Ираном значительно помогли стране преодолеть постсоветский кризис.

Было расширено сотрудничество между Арменией и Ираном в сферах энергетики, транспорта, охраны природы, здравоохранения, сельского хозяйства, науки, образования, культуры, межрегионального сотрудничества, а также был подписан ряд стратегических вопросов, соглашение (1995 год) и Договор (2004 год) о строительстве газопровода Иран-Армения, Соглашение о строительстве совместной гидроэлектростанции на реке Аракс (1995 год), Меморандум о взаимопонимании по строительству иранской нефти в Армению (2012 год) и т. д. [23].

Тем не менее до сих пор армяно-иранские торгово-экономические отношения еще не столь развиты. Объемы импорта из Армении в Иран, а также из Ирана в Армению все еще невелики. В ИРИ нет армянских инвестиций или же официальные данные об инвестициях Армении в ИРИ отсутствуют. Что касается иранских инвестиций в Армении, то эти инвестиции занимают очень малую часть армянских ПИИ. Это связано с многочисленными обстоятельствами. Например, надо учесть размеры рынка: рынок Армении очень мал для привлечения крупных инвестиций.

Вышеприведенные аргументы остались неизменными до 2015 года. Однако в 2015 году ситуация резко изменилась как с точки зрения Армении, так и для ИРИ. В 2015 году Армения присоединилась к Евразийскому экономическому союзу, обеспечив доступ для предпринимателей к многомиллионному рынку. Что касается Ирана, то для этой страны начиная с 2015 года сократились санкции, введенные западными странами. Это способствует повыше- 
нию прозрачности иранского рынка для других стран, в том числе для инвесторов из Армении. Таким образом, можно сказать, что 2015 год стал переломным для развития обеих стран, позволяющим в новом свете наблюдать за развитием армяно-иранских торговоэкономических отношений и разрабатывать на этой основе новые пути перспективного развития.

Статистические данные об инвестициях Ирана в Армению приведены в таблице 1.

Статистические данные свидетельствуют о том, что в рассматриваемый период иранские инвесторы инвестировали в следующих сферах экономики Армении - в сельское хозяйство, строительство, оптовую и розничную торговлю, в химическую промышленность и логистику.

В 2002-2016 годах самым привлекательным сектором в экономике Армении для иранских инвесторов была оптовая торговля, где были сделаны крупнейшие инвестиции, а наименее привлекательным сектором оказалось строительство, где было инвестировано всего 2300 долларов США [21].

Таблица 1

Иранские инвестиции в Армении в 2002-2016 годах [21], тыс. долларов

\begin{tabular}{|c|c|c|c|c|c|c|c|c|}
\hline \multicolumn{9}{|c|}{ Сферы } \\
\hline & Всего & $\begin{array}{c}\text { Сельское } \\
\text { хозяйство и } \\
\text { охота }\end{array}$ & $\begin{array}{c}\text { Строите } \\
\text { льство }\end{array}$ & $\begin{array}{c}\text { Оптовая } \\
\text { торговля }\end{array}$ & $\begin{array}{c}\text { Розничная } \\
\text { торговля }\end{array}$ & Логистика & $\begin{array}{c}\text { Химическая } \\
\text { промышленность }\end{array}$ & $\begin{array}{c}\text { Пищевая } \\
\text { промышленность }\end{array}$ \\
\hline 2002 & 1763 & 677 & 0 & 1086 & 0 & 0 & 0 & 0 \\
\hline 2003 & 457,2 & 0 & 2,3 & 417,6 & 8 & 29,3 & 0 & 0 \\
\hline 2004 & 39,2 & 0 & 0 & 0 & 0 & 0 & 39,2 & 0 \\
\hline 2005 & 119,7 & 0 & 0 & 37,2 & 0 & 0 & 82,5 & 0 \\
\hline 2006 & 195,3 & 0 & 0 & 88,9 & 0 & 0 & 106,4 & 0 \\
\hline 2007 & 154,7 & 0 & 0 & 0 & 0 & 0 & 154,7 & 0 \\
\hline 2012 & 0,5 & 0 & 0 & 0 & 0 & 0,5 & 0 & 0 \\
\hline 2014 & 45,6 & 0 & 0 & 0 & 0 & 45,6 & 0 & 0 \\
\hline 2015 & 545,8 & & & & & $-45,6$ & & 591,4 \\
\hline 2016 & 217,0 & & & & & & & 217,0 \\
\hline
\end{tabular}

На период с 2002 по 2016 год наиболее значительные инвестиции иранскими инвесторами в Республике Армения были сделаны в 2002 году. Эти инвестиции составили 1,5 млн долл. США. А наименьшие инвестиции были сделаны в 2012 году. Следует также отметить, что в 2008-2011 и 2013 годах иранская сторона не инвестировала в Армению, поэтому эти годы не были включены в таблицу.

В 2015-2016 годах для иранских инвесторов стала привлекательной сфера пищевой промышленности Армении. Этому способствовал особенно тот факт, что ряд иранских бизнесменов предпочли создать скотобойни в Армении. Это обеспечивает больше эффективности, чем импорт живых животных из Армении в ИРИ и организация их убоя в ИРИ, поскольку животные теряют вес при перемещении. Кроме этого, вкладывая средства в экономику Армении, инвесторы также получают доступ к рынку ЕАЭС на льготных условиях, которым не пользовались бы при инвестиции в Иране.

Что касается армяно-иранских торговых отношений, то они имеют многолетнюю историю и были обоснованы с первых дней независимости Армении. В то же время роль Исламской Республики Иран важна для Армении не только для экспорта в ИРИ, но и с точки зрения выхода на рынки других стран по морю. Как известно, Армения не имеет выхода к морю, и в основном для экспорта использует морские порты двух соседних стран - морские порты Грузии для выхода на рынки ЕС и России и морские порты Ирана для выхода в арабские и азиатские страны. 
Сперва рассмотрим взаимные торгово-экономические связи двух стран. Если на начальном этапе (1992 год) общий внешнеторговый оборот Армении составил 288,8 млн долларов [22], то уже в 1995 году товарооборот только с Ираном составил 125 млн долларов [20]. Это означает, что уже с первых дней независимости роль Ирана для Армении постепенно выросла с внешнеторговой точки зрения.

В 1996 году внешнеторговый оборот Армении и Ирана достиг 194 млн долларов. Иран был вторым крупным экономическим партнером Армении после России довольно долгое время. В 1999-2002 годах армяно-иранский товарооборот сократился до определенной степени и, в частности, в 2002 году составил 92,7 млн долларов, тем не менее Иран по-прежнему остался одним из крупнейших внешнеторговых партнеров Армении. Между тем следует отметить, что сокращение торговых темпов не было обусловлено потерей интереса друг к другу с экономической точки зрения. Просто некоторые из ранее импортируемых из ИРИ продуктов уже производились в Армении. Кстати говоря, иногда эти производства в Армении обосновались именно благодаря Ирану.

Например, объем обработанных строительных камней, импортированных из Ирана, резко снизился тогда, когда в Армении, а точнее - в Сюнике, был создан камнеобрабатывающий завод, который работал по передовым технологиям обрабатывания камней, внедренных из Ирана. Впоследствии аналогичные заводы по переработке камня были также созданы в других районах Армении. С 2002 году импорт из Ирана в Армению вырос. Рост импорта из ИРИ большими темпами продолжался особенно в период в 2004-2008 годов. В 2009 году, как в других, так и в данной сфере, импорт из Ирана пошел на спад, однако в последующие годы до 2013 года - опять-таки импорт из Ирана вырос. В 2013 году темпы опять снизились из-за санкций против Ирана, а в 2015-м это сокращение было обусловлено членством Армении в ЕАЭС и неопределенностью на начальном этапе.

Что касается экспорта из Армении в Иран, то надо отметить, что он не превысил 50 млн долларов до 2009 года. В 2009-2012 годах экспорт рос произвольно, но уже после 2012-го опять темпы экспорта снизились. Однако до сих пор объемы экспорта все еще находятся выше показателей 2009 года.

Причины снижения экспорта из Армении в Иран различны. Но мы в основном предполагаем, что самыми главными причинами этого являются санкции, введенные против Ирана западными странами, и нестабильность иранской национальной валюты, девальвация которой привела к повышению цен на импорт ИРИ, в том числе и из Армении.

Ниже приведен анализ армяно-иранского экспорта и импорта в 2000-2016 годах [24]. Существует несколько продуктов, которые импортируются и экспортируются одновременно.

В частности, постепенно сократился экспорт свинца и изделий из него, рудов, шлака и золы, черных металлов и изделий из Армении в Иран, а вместо этого Армения стала импортировать эти товары из Ирана. Это означает, что под влиянием определенных факторов производство данных товаров в Армении стало менее конкурентоспособным, а в ИРИ произошел обратный процесс, в результате которого экспорт этих товаров из Республики Армения в Иран был заменен импортом из ИРИ.

Но есть такие товары, при которых пошел обратный процесс. Например, сократился импорт мясных продуктов из Ирана в Армению, и взамен вырос экспорт данной товарной группы из Армении в Иран.

Некоторые товары (сахар и кондитерские изделия из сахара, какао и продукты из него, готовые продукты из зерна злаков, муки, крахмала или молока, органические химические соединения, фармацевтическая продукция) вообще не экспортировались в начале рассматриваемого периода, хотя в конце их экспорт уже был немалого объема. Этот факт говорит о том, что в рассматриваемый период времени производители данных товаров смогли достичь таких высот, которые позволили им выйти на иранский рынок.

А вот, например, наличие экспорта и импорта одновременно нескольких товаров (топливо минеральное, нефть, воски и битуминозные вещества, древесина и изделия из нее, древесный уголь, медь и изделия из нее, алюминий и изделия из него, реакторы ядерные, котлы, оборудование и механические устройства, компьютеры, электрические машины и оборудование, их части; телекоммуникационное оборудование; звукозаписывающая аппаратура; телевизионная 
записывающая аппаратура) объясняется тем, что армянские и иранские потребители имеют разные вкусы.

Хотя с точки зрения объемов экспорт из Армении в ИРИ вырос в рассматриваемый период, все-таки концентрация экспорта увеличилась, что может привести к очень нежелательным последствиям. В начале данного периода в экспорте из Армении в Иран более чем $1 \%$ занимали 10 товарных групп, но уже в 2016 году только 2 вида товаров занимали более чем $1 \%$ армянского экспорта в ИРИ. Тем не менее на основе принципов выявленного и потенциального сравнительного преимущества мы рассчитали самые эффективные секторы взаимной торговли РА - ИРИ.

На основе проведенных нами расчетов можно сказать, что в краткосрочном плане Армения может развивать экспорт следующих товаров в Иране: овцы и козы живые, земли инфузорные кремнистые и земли с удельным весом 1 или менее, электроэнергия, отходы и лом алюминиевый, станки для сверления, растачивания, фрезерования и т. д., аппаратура электрическая для коммутации и т. д., руды и концентраты, бритвы и лезвия.

Говоря о долгосрочном плане, можно с уверенностью сказать, что после ряда структурных изменений Армения сможет не только развивать, но и расширить экспорт товаров и товарных групп в Иране. Для долгосрочной перспективы эффективными считаются следующие товары: баранина или козлятина свежая, охлажденная или замороженная; пищевые субпродукты крупного рогатого скота, свиней, овец, коз, лошадей и т. д.; сухофрукты, в другом месте не поименованные или не включенные; смеси сухофруктов или орехов; гранит, порфир, базальт и т. д.; распиленные или нераспиленные и т. д., проволока алюминиевая, плиты, листы и ленты из алюминия, алюминиевая фольга, оборудование для сельского хозяйства и т. д.; птицеводства и т. д., включая инкубаторы, детали к нему; танки токарные для удаления металла, краны, клапаны, вентили и т. д. для труб, резервуаров и т. д. детали к ним; аккумуляторы электрические, включая сепараторы, их части, машины электрические и т. д., с индивидуальными функциями, в другом месте не поименованные или не включенные, их части.

Что касается перспектив взаимовыгодных армяно-иранских инвестиционных сфер, следует отметить, что в результате наших расчетов стало ясно, что для создания совместных предприятий наиболее эффективным сектором экономики Армении является горнодобывающая промышленность, в которой обе страны имеют выявленное сравнительное преимущество экспорта. Эффективными областями для иранских инвестиций в Республику Армения могут быть сферы пищевых продуктов, камней и стекл, а также производство металлических предметов.

Кстати, в некоторых случаях производство металлических изделий может быть логическим продолжением организации, созданной в области добычи металлической руды.

И наконец, нужно отметить, что для армянских инвесторов в ИРИ самыми благоприятными сферами могут быть производства растений и растительных продуктов, топлива, химикатов и пластмасс, в которых Исламская Республика Иран имеет выявленное сравнительное преимущество.

Область применения результатов. Рассмотренные в статье тезисы о взаимовыгодной двусторонней торговле, а также об эффективных инвестициях могут быть полезны для дальнейших исследований на эту темы, для авторов обучающих программ, а также для государственных органов Армении и Ирана при разработке программ развития двустороннего сотрудничества.

Выводы. Таким образом, можно сделать следующий вывод: торговое и инвестиционное сотрудничество между Арменией и Ираном обладает большим потенциалом, который еще не используется в полной мере.

Это может стать хорошей возможностью для Армении диверсифицировать как экспортную корзину, так и инвестиционный портфель. Таким образом, можно постепенно ослабить зависимость от одного или нескольких крупных инвесторов или торгового партнера, что будет способствовать дальнейшему устойчивому развитию экономики Армении.

Литература

1. Adam Smith. The Wealth of Nations. Book 4. Part 2. 1776 Ricardo D. The Principles of Political Economy and Taxation. Ch. 11, London, 1817.

2. Aiginger K. 2006. "Competitiveness: from a dangerous obsession to a welfare creating ability with positive externalities». Journal of Industrial Trade and Competition, 6. P. 63-66. 


\section{САРГСЯН Л.Н.}

ПЕРСПЕКТИВЫ РАЗВИТИЯ ТОРГОВОЭКОНОМИЧЕСКИХ ОТНОШЕНИЙ МЕЖДУ АРМЕНИЕЙ И ИРАНОМ

3. Barney J. B. (1991). Firm Resources and Sustained Competitive Advantage, Journal of Management, 17 (1).

P. 99-117.

4. Cho D. S. (1998). From National Competitiveness to Bloc and Global Competitiveness. Competitiveness Review. V. 8 (1). P. 11-23.

5. Dan Ben-David. Equalizing Ezchange: A Study of the Effects of Trade Liberalization, Quarterly Journal of Economices, 1993. P. 25-37.

6. Daniel Gros, Cinzia Alcidi. The Global Economy in 2030: Trends and Strategies for Europe. November 2013. P. 15-20.

7. De Long J., Summers L. Equipment Investment and Economic Growth. The Quarterly Journal of Economics. Vol. 106. No. 2 (May, 1991). P. 445-502.

8. Dollar D. and Kraay A. Trade, Growth and Poverty. The Economic Journal. Vol. 114. No. 493. Features (Feb., 2004). P. F22-F49.

9. Ezeala-Harrison F. 2005. «On the competing notions of international competitiveness». Advances in Competitiveness Research, 13(1): 80. P. 32.

10. IMF. Foreign Direct Investment: Trends, data availability, concepts and recording practices, 2004, P. 6.

11. Joel Mokyr. Mercantilism, the Enlightenment and the Industrial Revolution, 2003. P. 15-25

12. Kathuria V. (2002). Liberalisation, FDI and Productivity spillover - An Analysis of Indian Manufacturing Firms. Oxford Economic Papers 54. P. 688-718.

13. Krugman P. The Myth of Asia's Miracle, Foreign Affairs, 1994, P. 62-78.

14. Krugman/Obstfeld. International Economics. 2003, Chapter 2: Labor Productivity and Comparative Advantage: The Ricardian Model. P. 10-38.

15. Porter M. Competitive Advantage: Creating and Sustaining Superior Performance. New York, 1985. P. 112 -143 .

16. Siggel E. International Competitiveness and Comparative Advantage: A Survey and a Proposal for Measurement, Competition and Trade, 6 (2) (2006). P. 137-159.

17. Wacziarg R. and K. Horn Welch, Trade liberalization and growth: new evidence, The World Bank Economic Review. Vol. 22. No. 2 (2008). P. 187-231.

18. Бланк А. Инвестиционный менеджмент, Изд.; «Ника-Центр», 2004. - С. 129.

19. МкКинзи. Корп. Программа «Армения 2020», Ереван. -2005. - С. 232.

20. [An electronic resource]. Access mode: http://armstat.am/am, free. Heading from the screen.

21. [An electronic resource]. Access mode: http://armstat.am/am/?nid=246, free. Heading from the screen.

22. [An electronic resource]. Access mode: http://armstat.am/file/article/tntbar_91_98a_2.pdf, free. Heading from the screen.

23. [An electronic resource]. Access mode: http://mineconomy.am/up/files/CANK-188.pdf, free. Heading from the screen.

24. [An electronic resource]. Access mode: wits.worldbank.org, free. Heading from the screen.

\section{References:}

1. Adam Smith. The Wealth of Nations. Book 4. Part 2. 1776 Ricardo D. The Principles of Political Economy and Taxation. Ch. 11, London, 1817.

2. Aiginger K. 2006. "Competitiveness: from a dangerous obsession to a welfare creating ability with positive externalities». Journal of Industrial Trade and Competition, 6. P. 63-66.

3. Barney J. B. (1991). Firm Resources and Sustained Competitive Advantage, Journal of Management, 17 (1). P. 99-117.

4. Blank A. Invstment management. Nica-center. 2004. P. 129.

5. Cho D. S. (1998). From National Competitiveness to Bloc and Global Competitiveness. Competitiveness Review. V. 8 (1). P. 11-23.

6. Dan Ben-David. Equalizing Ezchange: A Study of the Effects of Trade Liberalization, Quarterly Journal of Economices, 1993. P. 25-37.

7. Daniel Gros, Cinzia Alcidi. The Global Economy in 2030: Trends and Strategies for Europe. November 2013. P. 15-20.

8. De Long J., Summers L. Equipment Investment and Economic Growth. The Quarterly Journal of Economics. Vol. 106. No. 2 (May, 1991). P. 445-502.

9. Dollar D. and Kraay A. Trade, Growth and Poverty. The Economic Journal. Vol. 114. No. 493. Features (Feb., 2004). P. F22-F49.

10. Ezeala-Harrison F. 2005. «On the competing notions of international competitiveness». Advances in Competitiveness Research, 13(1): 80. P. 32.

11. IMF. Foreign Direct Investment: Trends, data availability, concepts and recording practices, 2004, P. 6.

12. Joel Mokyr. Mercantilism, the Enlightenment and the Industrial Revolution, 2003. P. 15-25

13. Kathuria V. (2002). Liberalisation, FDI and Productivity spillover - An Analysis of Indian Manufacturing Firms. Oxford Economic Papers 54. P. 688-718.

14. Krugman P. The Myth of Asia's Miracle, Foreign Affairs, 1994, P. 62-78.

15. Krugman/Obstfeld. International Economics. 2003, Chapter 2: Labor Productivity and Comparative Advantage: The Ricardian Model. P. 10-38.

16. McKinsey. «Armenia 2020».Yerevan. 2005. 232 p.

17. Porter M. Competitive Advantage: Creating and Sustaining Superior Performance. New York, 1985. P. 112 -143 .

18. Siggel E. International Competitiveness and Comparative Advantage: A Survey and a Proposal for Measurement, Competition and Trade, 6 (2) (2006). P. 137-159. 
19. Wacziarg R. and K. Horn Welch, Trade liberalization and growth: new evidence, The World Bank Economic Review. Vol. 22. No. 2 (2008). P. 187-231.

20. [An electronic resource]. Access mode: http://armstat.am/am, free. Heading from the screen.

21. [An electronic resource]. Access mode: http://armstat.am/am/?nid=246, free. Heading from the screen.

22. [An electronic resource]. Access mode: http://armstat.am/file/article/tntbar_91_98a_2.pdf, free. Heading from the screen.

23. [An electronic resource]. Access mode: http://mineconomy.am/up/files/CANK-188.pdf, free. Heading from the screen.

24. [An electronic resource]. Access mode: wits.worldbank.org, free. Heading from the screen. 